\title{
Causalidade Entre Crédito Bancário e Nível de Atividade Econômica na Região Metropolitana de São Paulo: Algumas Evidências Empíricas ${ }^{\star}$
}

\author{
- DANIEL REICHSTUL *
}

- Gilberto Tadeu Lima **

\begin{abstract}
RESUMO
Este artigo contribui para o entendimento da causalidade entre crédito bancário e atividade econômica na Região Metropolitana de São Paulo (RMSP). Questões têm sido levantadas quanto à direção da causalidade, à Granger, prevalecente em economias nacionais, e uma ênfase local ainda não contemplada na literatura é dada aqui. Analisa-se a relação entre diferentes modalidades de crédito bancário e um indicador de atividade econômica na RMSP entre janeiro de 1992 e dezembro de 2003, com um modelo de Vetores Auto-regressivos bivariado tendo detectado uma causalidade bidirecional.
\end{abstract}

\section{Palavras-CHAVE}

desenvolvimento financeiro local, crédito bancário, atividade econômica

\section{AbSTRACT}

This study contributes to the understanding of the causality between banking credit and economic activity in the Metropolitan Region of São Paulo (MRSP). Questions have been raised as to the prevailing Grangercausality for national economies, and a local approach that has not yet been followed in the empirical literature is pursued here. It is dealt with the relationship between several banking credit modalities and an indicator of economic activity in the MRSP from January 1992 to December 2003, with a bivariate Autoregressive Vector model having found a birectional causality.

KEY WORDS

local financial development, banking credit, economic activity

JEL Classification

$R / 2, G 2 I$

- Cabem agradecimentos a Ciro Biderman, Eduardo Haddad e a um parecerista anônimo por valiosas observações e sugestões. Quanto aos eventuais equívocos e imprecisões remanescentes, porém, valem, desde logo, as habituais isenções. Os autores são igualmente gratos ao CNPq por financiamento de pesquisa.

* Mestre em Teoria Econômica pelo IPE-FEA-USP. E-mail: daniel.reichstul@br.abnamro.com.

* Professor do Departamento de Economia da FEA-USP. E-mail: giltadeu@usp.br. Endereço para contato: Departamento de Economia - FEA-USP - Av. Prof. Luciano Gualberto, 908. São Paulo - SP - CEP 05508-0I0. (Recebido em março de 2005. Aceito para publicação em janeiro de 2006). 


\section{INTRODUÇÃO}

Muito embora gere certas divergências, parece haver, na literatura econômica, certo consenso de que o desenvolvimento financeiro afeta positivamente a dinâmica da atividade econômica. De fato, a teoria econômica atribui ao crédito, desde que ofertado em condições adequadas de prazos, custos e quantidades, a possibilidade de concretizar as oportunidades de investimento promissoras ex ante.

Nesse contexto, a principal preocupação deste artigo é averiguar se a conhecida intensidade da concentração dos intermediários financeiros na Região Metropolitana de São Paulo - RMSP - pode estar associada a um padrão de desenvolvimento financeiro que influa de algum modo no crescimento econômico dessa região. Cabe esclarecer que não se pretende analisar as origens dessa concentração, mas somente analisar a relação de causalidade, se alguma, entre alguns aspectos da atividade econômica da RMSP e o seu desenvolvimento financeiro.

A cidade de São Paulo consolidou-se definitivamente, ao longo da década de 1990, como o centro financeiro nacional, em detrimento das demais áreas do País e, principalmente, da cidade do Rio de Janeiro, que teve grande parte de suas atividades de intermediação financeira transferida para aquele local. Em razão da significativa concentração do sistema financeiro e também da centralização das atividades industriais, comerciais e de serviços, chega-se naturalmente à questão da possível existência de alguma relação de causalidade entre o desenvolvimento financeiro da RMSP e suas atividades econômicas.

Idealmente, seria necessário contar com uma medida que representasse a intensidade com que os intermediários financeiros da região atuam no sentido de facilitar o processo econômico. Especificamente, essa medida deveria refletir o volume de transação de bens e serviços, a capacidade de diversificação de riscos por meio da mobilização de fundos emprestáveis, a eficiência da alocação de recursos, a intensidade com que os interesses dos credores são zelados, o acesso ao crédito - enfim, todas as facilidades que a intermediação financeira traz à atividade econômica. Sem dúvida, a existência de um indicador que abrangesse todos esses elementos permitiria o experimento ideal para se analisar a relação entre os desenvolvimentos financeiro e econômico locais. Como, porém, esse indicador não existe, são buscadas medidas que captem, de alguma forma, a eficiência dos intermediários financeiros. A solução usual é o uso de diferentes variáveis que, individualmente, refletem somente uma determinada faceta do funcionamento da intermediação financeira, mas, analisadas em conjunto, contribuem para o entendimento da interação dos setores financeiro e real. 
Nesse sentido, o presente artigo tem como foco a relação entre variáveis creditícias e de atividade econômica na RMSP para o período de janeiro de 1992 a dezembro de 2003. Adotar-se-á o instrumental de Vetores Auto-regressivos - VAR com o propósito de estimar, por meio do teste de Granger, a direção de causalidade entre essa variável financeira e o indicador de atividade real representado pelo Índice de Movimentação Econômica (IMEC), desenvolvido pela Fundação Instituto de Pesquisas Econômicas (FIPE).

Posto que o Brasil possui um sistema financeiro eminentemente bancário, serão utilizadas como indicador de desenvolvimento financeiro local diferentes modalidades do crédito, em termos per capita, negociadas na região. Assim sendo, a principal inovação deste artigo está na avaliação empírica da causalidade entre desenvolvimento financeiro e atividade econômica sob uma perspectiva local centrada em dimensões específicas da atividade econômica na RMSP. Como veremos à frente, os testes correspondentes indicaram a existência de uma relação causal de mão dupla em que tanto o desenvolvimento financeiro causa o econômico quanto este causa aquele.

O restante do artigo se divide em quatro seções. A próxima resgata os principais resultados teóricos e empíricos que fundamentam o debate sobre o papel do crédito no desenvolvimento econômico. A seção seguinte apresenta um panorama geral do crédito no Brasil e discorre sobre o processo de concentração deste na RMSP, ao longo da década de 1990, enquanto a próxima reporta e analisa os testes de causalidade correspondentes. Na última seção, por sua vez, tecem-se considerações finais.

\section{RESGATE DA LITERATURA TEÓRICA E EMPÍRICA}

$\mathrm{O}$ argumento central para uma conexão positiva entre os setores financeiro e produtivo está baseado na idéia de que os instrumentos, as instituições e os mercados financeiros têm, como função última, drenar e minimizar os custos de transação e de informação inerentes a qualquer atividade de troca. Prover serviços financeiros envolve diferentes custos (com pesquisa de projetos rentáveis, acompanhamento da situação patrimonial das empresas, elaboração de mecanismos de redução de risco etc.) que se não ficassem a cargo dos intermediários financeiros que, ao se especializarem nessa atividade adquirem expertise e obtêm ganhos de escala e de escopo, deveriam ser encargo dos investidores individuais.

Levine (1997), por exemplo, examina dois canais pelos quais as funções desempenhadas pelo sistema financeiro podem impactar o crescimento econômico: acumulação de capital e inovação tecnológica. O sistema financeiro afetaria a formação bruta de capital ao alterar a taxa de poupança e/ou ao realocar a poupança entre diferentes 
tecnologias produtoras de capital, o que aumentaria a produtividade do investimento. Porém, uma mudança na taxa de poupança só atingiria momentaneamente o crescimento da renda. Para se entender como se desenvolve esse processo, deve-se salientar o aspecto funcional do sistema financeiro, que encerra tanto a oferta de serviços quanto a infra-estrutura do sistema: instituiçôes, mercados e instrumentos financeiros. Os serviços são engendrados pelas fricções do mercado e acabam por influir nas decisões e na alocação de poupança. As funções desempenhadas por esse sistema podem alterar a taxa de inovação tecnológica de diferentes formas, de modo a intervir no crescimento de estado estacionário.

O estudo das diferenças de desenvolvimento regional, por sua vez, faz parte de uma literatura da qual fazem parte, entre outros, autores como Myrdal (1957), Perroux (1967), Hirschman (1958) e Kaldor (1970). Entretanto, apesar de essa literatura contemplar o setor financeiro das regiões, seu tratamento faz-se sob a perspectiva mais ampla de analisar o desenvolvimento das regióes ou da localidade, sem uma análise necessariamente direta do papel específico do desenvolvimento da intermediação financeira para a dinâmica econômica regional ou local. Muito embora o crédito seja um elemento importante, com a potencialidade de dinamizar o crescimento de determinada região, sua atuação é mais uma conseqüência ou resposta ao processo de industrialização ou desenvolvimento já em curso. Sob esse aspecto, o crédito não lidera o desenvolvimento, mas segue-o.

No que concerne à oferta de crédito regional, especificamente, a literatura preocupase com a integração dos sistemas bancários regionais com fatores (responsáveis pela segmentação dos mercados financeiros e, consequientemente, pelas diferenças regionais de oferta de crédito e de taxas de juros) que criam dificuldades à perfeita mobilidade de capitais. Com visões distintas sobre a questão, destacam-se, por exemplo, Mishkin (1998), Zimmerman (1995), Dow (1994), Martin e Minns (1995) e Chick e Dow (1988). Em termos da relação regional entre os níveis de desenvolvimento financeiro e econômico, merecem menção os estudos de Jayaratne e Strahan (1996) e Guiso, Sapienza e Zingales (2002), que revelam um impacto positivo e significativo do desenvolvimento financeiro local sobre o crescimento econômico local. O estudo de Guiso, Sapienza e Zingales (2002) propóe explicitamente um indicador local de desenvolvimento financeiro para as províncias italianas e identifica sua influência sobre o desenvolvimento econômico de cada região. Seus resultados sugerem que em países com regiốes integradas em nível de regulação e supervisão e com sistemas financeiros não tão desenvolvidos a ponto de serem eliminados os custos referentes à distância, $\mathrm{o}$ grau de desenvolvimento financeiro local é importante para o crescimento econômico e pode ser determinante do sucesso econômico de uma localidade, mesmo que esta seja parte de um ambiente de livre circulação de capitais. O Brasil parece inserir-se nesse grupo, dada a sua grande dimensão geográfica e a sua unidade de regulação fi- 
nanceira, isto é, por ter legislação financeira única para todos os Estados. No entanto, ao menos para a RMSP durante a década de 1990, os resultados a serem apresentados nas seções seguintes não confirmam plenamente essa percepção.

Especificamente sobre o Brasil, Matos (2002) procura verificar a direção de causalidade à Granger entre desenvolvimento financeiro e crescimento econômico, para o período entre 1947 e 2000. Os resultados dão suporte à existência de uma relação unidirecional que vai do desenvolvimento financeiro para o crescimento econômico. Por sua vez, Marques e Porto (2003) testam a direção de causalidade entre o desenvolvimento financeiro dos mercados bancário e de capitais e o crescimento econômico brasileiro para o período de 1950 a 2000 e chegam às mesmas conclusões de Matos (2002).

Também com foco na oferta de crédito regional, o trabalho de Castro (2002) examina o relacionamento entre a moeda e o espaço econômico delimitado pelas regiões de São Paulo, Rio de Janeiro, Belo Horizonte, Curitiba, Salvador e as áreas de influência desses centros, durante o período 1988/2000. O autor concluiu que quanto maior o dinamismo econômico da região e sua produtividade média do trabalho, maior sua capacidade em reter depósitos e menor sua preferência pela liquidez. Essa influência do desenvolvimento econômico sobre a distribuição da atividade bancária também foi constatada, empiricamente, para o caso brasileiro, por Sicsú e Crocco (2003). Seus resultados indicam que o volume de renda monetária, assim como sua distribuição espacial e pessoal, explica, em boa medida, a distribuição das agências bancárias pelo Brasil.

A contribuição de Alexandre, Biderman e Lima (2004) inova, ao analisar a convergência no crescimento entre os Estados brasileiros de 1988 a 2001 e incluir indicadores de oferta de crédito entre as variáveis explicativas tradicionalmente utilizadas em estudos desse tipo. Dos resultados infere-se que, em geral, o crédito diminui a "meia vida", ou seja, aumenta a velocidade de convergência. Esse resultado está em consonância com os obtidos, em esfera nacional, por Marques e Porto (2003) e Matos $(2002,2003)$.

Os trabalhos de Vasconcelos et alii (2003) e Castro (2002) demonstram a forte concentração financeira no Estado e na RMSP e como ela reúne características que compóem um ambiente propício ao florescimento das atividades de intermediação financeira. O que não fica claro, daí o propósito do estudo empírico desenvolvido no âmbito deste artigo, é se a concentração financeira em São Paulo significa uma vantagem comparativa da região com as demais, ou se é apenas reflexo/decorrência do crescimento econômico regional. 
Durante os anos 1970, como resultado das políticas de investimento do II PND e de incentivo de desenvolvimento e de integração das diferentes regióes do País, assistiuse ao movimento de desconcentração da produção industrial e ao avanço da indústria nos diferentes Estados brasileiros, com exceção de São Paulo e do Rio de Janeiro, cujas participações, relativas ao total nacional, foram reduzidas. (Pacheco, 1996). O expressivo e contínuo crescimento da RMSP aliado à concentração econômica e populacional findou levando o local a apresentar deseconomias de aglomeração, a ponto de Townroe e Keen (1984) proporem que se considere a RMSP como o primeiro caso de reversão da polarização do Terceiro Mundo. Porém, essa tendência não é consensual. Segundo Azzoni (1986), por exemplo, as economias de aglomeração são regionais e não somente urbanas. Nesse contexto, a desconcentração se dá de maneira intraregional, fenômeno que alguns autores denominam de "interiorização" da indústria paulista.

Diniz (1993), porém, discorda de Azzoni (1986), pois entende que há, de fato, um processo de desconcentração decorrente da ampliação das economias de aglomeração de cidades do interior de São Paulo e de outros Estados e das deseconomias que a RMSP passou a produzir após anos de crescimento. Todavia essa desconcentração não se configura como um processo nacional. Pacheco (1996) segue a linha de Diniz (1993), no entanto busca requalificar o debate e declara que o processo de desconcentração regional continua, porém sob a égide de uma nova dinâmica, manifesta pela flagrante fragmentação da economia nacional em oposição ao crescimento solidário das regiões. Todavia, quanto a São Paulo, especificamente, Pacheco (1996) conclui que embora tenha ocorrido desconcentração não há reversão da polarização, pois não existem no País alternativas de polarização externas à metrópole. Neste sentido, sua análise aproxima-se da de Azzoni (1986).

Os resultados da Pesquisa da Atividade Econômica Paulista - PAEP - de 2001, aplicada pela Fundação SEADE, parecem confirmar esse diagnóstico. Na comparação com a pesquisa de 1996, os dados de 2001 não deixam dúvidas sobre a presença de consistente núcleo na RMSP, complementado pela intensa atividade nas regióes administrativas do entorno. O processo de "interiorização" também ganha força nos anos mais recentes. A participação da RMSP na atividade econômica do Estado decresce de 60\%, em 1996, para 53\%, em 2001, em benefício da área circunvizinha.

Definitivamente, o setor terciário do Estado de São Paulo concentra-se na RMSP que, em 2001, era responsável por $70 \%$ de todo o valor adicionado dos serviços do Estado (52\% na capital). No caso dos ligados à atividade econômica, a participação é ainda mais expressiva: $87 \%$ dos serviços técnicos prestados às empresas, $79 \%$ dos auxiliares prestados às empresas, $95 \%$ dos de telecomunicaçôes e $86 \%$ das atividades de informática. No resto do Estado a relevância do setor é pontual ou associada a 
alguns serviços muito específicos, enquanto aqueles voltados à atividade econômica têm presença mais discreta. Apesar de a indústria ser responsável por $52 \%$ do valor adicionado do Estado, o setor terciário é o que mais emprega (cerca de 50\% do total ocupado nos três setores: indústria, comércio e serviços), com participação bastante significativa no valor adicionado (39\%).

É essencial assinalar a característica de interdependência dos setores na economia paulista. $\mathrm{O}$ de serviços está intimamente unido à indústria, principalmente pelo fato de o segmento de serviços auxiliares às empresas, tanto em número de ocupados quanto em valor adicionado, ser o maior do setor, seguido pelo de transportes, e em seguida, respectivamente, pelo de serviços técnicos às empresas, pela saúde e pelas telecomunicações.

Os resultados da PAEP não só confirmam as idéias de Pacheco (1996) e Azzoni (1986), como dão apoio ao novo conceito de centralidade proposto por Tinoco (2001). Segundo o autor, é necessário redefinir-se a concepção de centralidade da RMSP diante de nova dinâmica de expansão industrial, apoiada na ciência e na tecnologia e com reduzida demanda incremental por recursos naturais, como o foi o caso do crescimento e do movimento de desconcentração dos anos 1970 e 1980. Sua hipótese é que a centralidade de uma economia do conhecimento define-se pela capacidade de a região criar um ambiente inovador, que é altamente dependente da aglomeração de atividades definidas, como os serviços à produção (serviços bancários, consultoria, advogados, entre outros). Neste sentido, a RSMP finda sendo espaço privilegiado para o processo de difusão de inovações, porque apresenta elevada participação desses serviços.

\section{CRÉDITO NO BRASIL E SUA CONCENTRAÇÃO NA RMSP}

Em paralelo ao processo de desconcentração industrial e/ou de "interiorização" da indústria do Estado e da RMSP nos anos 1980 e 1990, verificaram-se grandes transformações no sistema financeiro brasileiro, principalmente na última década. Sendo assim, esta seção procurará, inicialmente, traçar um panorama geral da evolução do mercado de crédito no Brasil e, em seguida, apresentará o processo de concentração bancária e financeira que se deu na RMSP nos últimos anos.

De fato, a razão crédito/PIB no Brasil é muito reduzida quando comparada à de outros países. Essa proporção tem declinado ao longo dos últimos anos, o que deveria ser motivo de apreensão. Enquanto no início de 1995 representava 35\% do PIB, em 2003 caiu para $26,4 \%$. A literatura mostra que esse declínio é resultado da adoção de regras mais restritivas do que as previstas pelos acordos da Basiléia, a partir de meados dos anos 1990. (Sobrinho, 2003; Lima, 2005). Outro entrave ao financiamento é o 
excessivo spread bancário, ainda que se considere a tendência de queda ensaiada nos últimos anos. Após a desvalorização cambial de janeiro de 1999, os spreads para as pessoas jurídicas e físicas reduzem-se, porém estacionam em um patamar ainda excessivamente elevado. Em dezembro de 2003, os valores eram, respectivamente, de 51\% e $26 \%$. Ademais, a maturidade das diferentes operações de crédito é demasiadamente curta, em média cerca de 7 meses (como se verifica na próxima tabela), de modo que os empréstimos de prazo mais longo se resumem aos realizados pelo BNDES ou a recursos obtidos, no exterior, pelas grandes empresas.

\section{TABELA 1 - PRAZO MÉDIO DAS OPERAÇÕES DE CRÉDITO PREFIXADAS COM RECURSOS LIVRES (EM DIAS) E PARTICIPAÇÃO NO CRÉDITO LIVRE TOTAL}

\begin{tabular}{|c|c|c|c|c|c|c|c|c|}
\hline \multirow[b]{2}{*}{ Modalidade } & \multicolumn{2}{|c|}{ Dez 2000} & \multicolumn{2}{|c|}{ Dez 2001} & \multicolumn{2}{|c|}{ Dez 2002} & \multicolumn{2}{|c|}{ Dez 2003} \\
\hline & $\%$ & PM & $\%$ & PM & $\%$ & PM & $\%$ & PM \\
\hline Capital de giro & $12,9 \%$ & 138 & $10,82 \%$ & 162 & $10,59 \%$ & 173 & $9,2 \%$ & 191 \\
\hline Conta garantida & $9,2 \%$ & 23 & $8,36 \%$ & 24 & $7,60 \%$ & 23 & $7,5 \%$ & 23 \\
\hline Aquisição de bens PJ & $2,3 \%$ & 362 & $3 \%$ & 620 & $3 \%$ & 312 & $2,8 \%$ & 313 \\
\hline Vendor & $7,2 \%$ & 79 & $6 \%$ & 82 & $6 \%$ & 70 & $5,3 \%$ & 75 \\
\hline Hot money & $0,6 \%$ & 13 & $0 \%$ & 14 & $0 \%$ & 10 & $0,2 \%$ & 11 \\
\hline Desconto de duplicatas & $6,0 \%$ & 38 & $5 \%$ & 40 & $5 \%$ & 32 & $5,4 \%$ & 31 \\
\hline Desconto de promissórias & $1,0 \%$ & 37 & $1 \%$ & 34 & $0 \%$ & 34 & $0,2 \%$ & 35 \\
\hline Financiamento imobiliário PJ & $0,2 \%$ & 1228 & $0 \%$ & 390 & $0 \%$ & 123 & $0,1 \%$ & 228 \\
\hline Outros PJ & $8,0 \%$ & 100 & $7 \%$ & 49 & $7 \%$ & 64 & $7,5 \%$ & 92 \\
\hline Cheque especial & $7,4 \%$ & 20 & $7 \%$ & 20 & $7 \%$ & 21 & $6,5 \%$ & 20 \\
\hline Crédito especial & $17,9 \%$ & 182 & $20 \%$ & 195 & $20 \%$ & 217 & $21,8 \%$ & 225 \\
\hline Cartão de crédito PF & $1,9 \%$ & 50 & $2 \%$ & 46 & $4 \%$ & 28 & $3,9 \%$ & 26 \\
\hline Financiamento imobiliário PF & $0,8 \%$ & 5059 & $0 \%$ & 1570 & $0 \%$ & 1997 & $0,3 \%$ & 1877 \\
\hline Aquisição de veículos PF & $17,8 \%$ & 512 & $22 \%$ & 516 & $22 \%$ & 517 & $21,9 \%$ & 503 \\
\hline Aquisição de outros bens PF & $3,7 \%$ & 147 & $3 \%$ & 172 & $4 \%$ & 165 & $3,9 \%$ & 155 \\
\hline Outros PF & $2,9 \%$ & 106 & $3 \%$ & 118 & $4 \%$ & 149 & $3,6 \%$ & 134 \\
\hline Total/PM & $100,00 \%$ & 221,00 & $100 \%$ & 209 & $100,01 \%$ & 218,00 & $100,02 \%$ & 219,00 \\
\hline
\end{tabular}

Fonte: Banco Central do Brasil. Não há dados disponíveis para os anos anteriores.

Do ponto de vista regional, o processo de transformação das atividades financeiras domésticas tem correspondente dimensão local-geográfica, isto é, no bojo do processo de transformação do sistema financeiro brasileiro, verificou-se elevada concentração das atividades financeiras na cidade de São Paulo, que, tradicionalmente centro financeiro do País, passou a abrigar todo o cerne da atividade financeira nacional, em detrimento, principalmente, do Rio de Janeiro. 
A concentração do mercado bancário em São Paulo é enorme. Em 2003, dos vinte maiores bancos, exceto o Banco do Brasil e a Caixa Econômica Federal (CEF), quatorze $(70 \%)$ tinham sede no Estado de São Paulo. No caso dos vinte e um bancos de investimento brasileiros, quatorze (67\%) possuem sede em São Paulo, e dos dez maiores, oito, no Estado. Das vinte maiores financeiras brasileiras, 15 (75\%) também estão sediadas no Estado. Além dessas instituições, a cidade hospeda mais de 50\% dos setores de seguros e de previdência, de empresas de corretagem de câmbio e de valores mobiliários (corretoras), de distribuidoras de câmbio e valores mobiliários (distribuidoras), além do segmento de cartões de crédito, que cresceu expressivamente nos anos 1990 e tem cerca de 80\% dos seus usuários na região Sudeste.

As operações de crédito, financiamentos e empréstimos e títulos descontados também se concentraram no Estado e na RMSP, como demonstram os próximos gráficos. Empréstimos são operações sem destinação específica ou sem vínculo com a comprovação da aplicação dos recursos, como o capital de giro, como os empréstimos pessoais e os adiantamentos para depositantes. Já financiamentos são as operações com destino específico, vinculadas com a comprovação da aplicação dos recursos, como, por exemplo, os financiamentos de parques industriais, de máquinas e equipamentos, de bens de consumo durável etc.

Em 1988, a RMSP era responsável por cerca de 22\% do total de crédito nacional; em 2003, passou para 39\%. O Estado do Rio de Janeiro, que em 1988 detinha cerca de $25 \%$ do total de crédito brasileiro, foi o centro que mais cedeu espaço para São Paulo, e em 2003 concentrava apenas 8\%. A concentração dos empréstimos e títulos descontados apresenta evolução mais suave, porém significativa. Ocorre no Estado de São Paulo, que em dezembro de 1988 detinha cerca de 50\% do total nacional, e em 2003 chegou a $57 \%$, ao passo que a RMSP e o Estado do Rio perderam espaço, e se em 1988 detinham 38\% e 17\%, em 2003, concentravam apenas 35\% e 10\%, respectivamente. Por fim, a modalidade financiamentos foi a que mais se concentrou no Estado e na RMSP. Em 1988, o Estado detinha cerca de 26\%, e a RMSP e o Estado do Rio, 23\% cada. Em 2003, o Estado de São Paulo passou para 72\%, a RMSP para $48 \%$ e o Estado do Rio para meros $6 \%$.

O avanço dessa concentração creditícia no Estado de São Paulo parece associado ao aludido processo de "interiorização" da indústria. Embora a RMSP tenha cedido parte de suas indústrias para o interior do Estado e para outras regiões metropolitanas, como verificou Diniz (1993), a concentração das atividades financeiras e da concessão das diferentes variáveis de crédito analisadas parece muito mais associada às economias de aglomeração que a praça de São Paulo e seu entorno oferecem do que à questão industrial propriamente dita. 


\section{GRÁFICO 1 - PARTICIPAÇÃO REGIONAL NO TOTAL DE CRÉDITO BRASILEIRO}

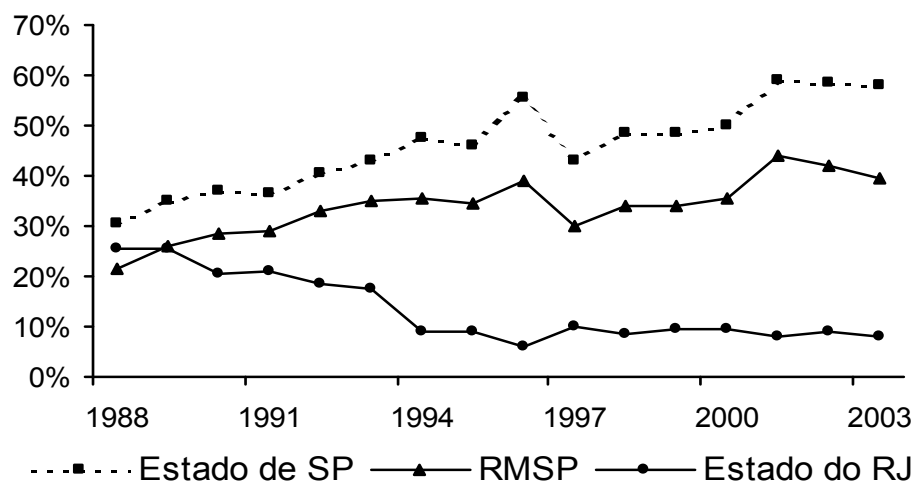

Fonte: Sisbacen. Elaboração Própria.

GRÁFICO 2 - PARTICIPAÇÃO REGIONAL NO TOTAL DE EMPRÉSTIMOS E TÍTULOS DESCONTADOS

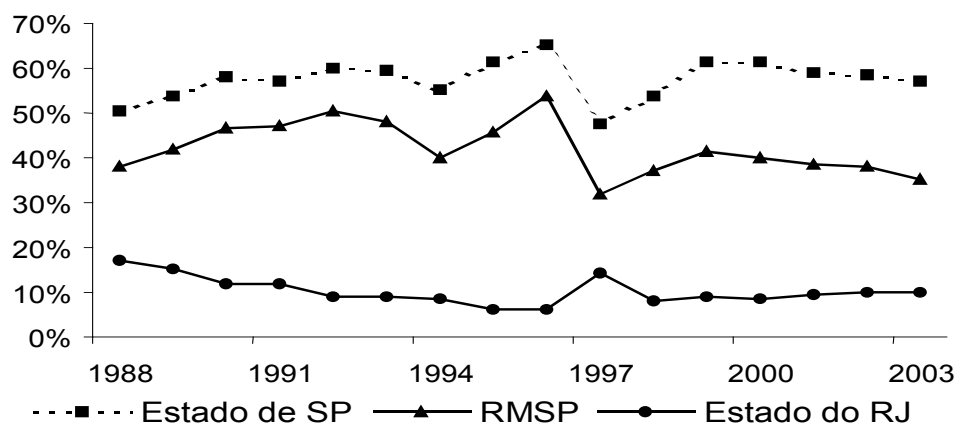

Fonte: Sisbacen. Elaboração Própria.

GRÁFICO 3 - PARTICIPAÇÃO REGIONAL NO TOTAL DE FINANCIAMENTO

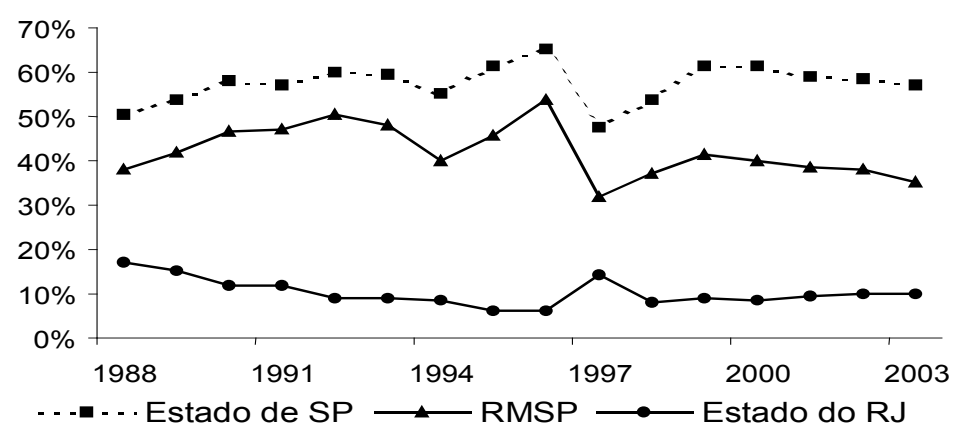

Fonte: Sisbacen. Elaboração Própria. 
Enquanto ocorreu um processo de concentração das operações bancárias na região de São Paulo, como ilustraram os gráficos anteriores, a distribuição das agências bancárias no País não se alterou significativamente ao longo dos anos 1990. O reflexo disso é a relação operações bancárias por agência tornar-se muito maior na cidade de São Paulo do que nas demais regiões. Além disso, em todo o período analisado, a relação operação bancária/agência na cidade de São Paulo é várias vezes superior à média nacional, ao contrário do que ocorre na maioria das outras áreas, diferença esta que se intensificou ao longo da última década. Paralelamente, a cidade do Rio de Janeiro sofreu uma relativa desconcentração bancária, especialmente do ponto de vista do volume de operações bancárias por agência. O destaque fica por conta das operações de crédito. Em 1988, a relação operações de crédito/agência bancária na cidade do Rio de Janeiro correspondia a 505\% da média nacional, superior inclusive à taxa de São Paulo. Em dezembro de 2003, essa cifra caiu para $112 \%$.

Os depósitos bancários apresentam leve concentração na cidade de São Paulo, embora o Estado tenha participação diminuída nesse período, porém quando se abrem os depósitos bancários, verifica-se, entre as rubricas "a vista" e "a prazo mais longo" (depósitos de poupança e a prazo), que a cidade de São Paulo concentra significativamente os últimos. Entre 1988 e 2003, a concentração desses depósitos na capital paulista evolui de $34,5 \%$ para $37 \%$.

TABELA 2 - DISTRIBUIÇÃO DOS DEPÓSITOS BANCÁRIOS NO BRASIL, EM \%

\begin{tabular}{lrrrrrrrrrrrrrrrr}
\hline & 1988 & 1989 & 1990 & 1991 & 1992 & 1993 & 1994 & 1995 & 1996 & 1997 & 1998 & 1999 & 2000 & 2001 & 2002 & 2003 \\
\hline RJ (cidade) & 10,9 & 13,4 & 9,8 & 9,8 & 12,3 & 11,9 & 10,7 & 12,0 & 11,9 & 9,8 & 10,0 & 9,5 & 8,2 & 8,6 & 8,5 & 8,1 \\
SP (cidade) & 32,9 & 33,3 & 37,6 & 38,5 & 39,8 & 39,6 & 35,7 & 38,6 & 42,1 & 42,5 & 36,2 & 40,2 & 42,0 & 39,4 & 33,3 & 35,2 \\
Resto Est. SP & 21,5 & 18,2 & 16,3 & 14,9 & 14,5 & 16,7 & 13,5 & 12,3 & 12,2 & 12,6 & 15,1 & 11,4 & 11,2 & 11,9 & 18,8 & 14,4 \\
Resto Reg. SE & 8,1 & 6,4 & 8,7 & 8,5 & 9,6 & 10,2 & 9,6 & 6,4 & 5,8 & 6,4 & 7,2 & 8,3 & 7,7 & 7,3 & 8,6 & 9,7 \\
Demais regiões & 26,6 & 28,7 & 27,6 & 28,2 & 23,8 & 21,6 & 30,5 & 30,7 & 28,0 & 28,7 & 31,5 & 30,5 & 30,8 & 32,8 & 30,8 & 41,0 \\
\hline
\end{tabular}

Nota: Posição em dezembro de cada ano. Fonte: Sisbacen. Elaboração própria.

TABELA 3 - DISTRIBUIÇÃO DOS DEPÓSITOS A VISTA NO BRASIL, EM \%

\begin{tabular}{lrrrrrrrrrrrrrrrr}
\hline & 1988 & 1989 & 1990 & 1991 & 1992 & 1993 & 1994 & 1995 & 1996 & 1997 & 1998 & 1999 & 2000 & 2001 & 2002 & 2003 \\
\hline RJ (cidade) & 12,4 & 19,1 & 11,3 & 11,3 & 12,8 & 10,2 & 9,9 & 10,0 & 10,5 & 10,3 & 10,1 & 10,4 & 9,4 & 9,5 & 10,8 & 10,7 \\
SP (cidade) & 19,4 & 23,6 & 22,8 & 20,7 & 19,0 & 21,2 & 19,8 & 22,0 & 21,4 & 22,8 & 20,9 & 23,4 & 22,5 & 21,4 & 22,8 & 21,6 \\
Resto Est. SP & 14,5 & 14,5 & 16,5 & 16,6 & 16,5 & 16,1 & 17,8 & 17,4 & 15,9 & 16,2 & 16,0 & 15,7 & 16,1 & 15,5 & 15,2 & 15,1 \\
Resto Reg. SE & 10,7 & 9,8 & 12,1 & 12,6 & 11,3 & 11,0 & 12,2 & 11,0 & 10,4 & 10,9 & 12,0 & 11,6 & 11,6 & 11,5 & 11,0 & 11,7 \\
Demais regiões & 43,0 & 32,9 & 37,2 & 39,0 & 40,3 & 41,5 & 40,4 & 39,6 & 41,9 & 39,8 & 41,0 & 38,9 & 40,4 & 42,1 & 40,2 & 42,7 \\
\hline
\end{tabular}

Nota: Posição em dezembro de cada ano. Fonte: Sisbacen. Elaboração própria. 
TABELA 4 - DISTRIBUIÇÃO DE OUTROS DEPÓSITOS (EXCETO A VISTA) NO BRASIL, EM \%

\begin{tabular}{lrrrrrrrrrrrrrrrr}
\hline & 1988 & 1989 & 1990 & 1991 & 1992 & 1993 & 1994 & 1995 & 1996 & 1997 & 1998 & 1999 & 2000 & 2001 & 2002 & 2003 \\
\hline RJ (cidade) & 10,7 & 13,1 & 9,5 & 9,6 & 12,2 & 11,9 & 10,8 & 12,1 & 12,0 & 9,7 & 10,0 & 9,4 & 8,1 & 8,5 & 8,1 & 7,8 \\
SP (cidade) & 34,5 & 33,9 & 40,6 & 41,1 & 41,2 & 40,4 & 37,5 & 39,8 & 43,2 & 44,2 & 37,6 & 42,1 & 44,4 & 41,6 & 34,8 & 36,9 \\
Resto Est. SP & 22,4 & 18,4 & 16,3 & 14,6 & 14,4 & 16,8 & 13,0 & 12,0 & 12,0 & 12,3 & 15,0 & 10,9 & 10,6 & 11,4 & 19,4 & 14,4 \\
Resto Reg. SE & 7,8 & 6,2 & 8,0 & 7,9 & 9,5 & 10,2 & 9,4 & 6,1 & 5,6 & 6,0 & 6,7 & 7,9 & 7,3 & 6,8 & 8,3 & 9,4 \\
Demais regiões & 24,7 & 28,4 & 25,7 & 26,6 & 22,7 & 20,8 & 29,4 & 30,1 & 27,3 & 27,7 & 30,6 & 29,6 & 29,6 & 31,7 & 29,4 & 40,7 \\
\hline
\end{tabular}

Nota: Posição em dezembro de cada ano. Fonte: Sisbacen. Elaboração própria.

De fato, a concentração da atividade financeira na macrorregião de São Paulo não é fortuita. Como indicam Alexandre, Lima e Canuto (2005), um elemento a ser considerado é a distribuição local do PIB, conforme o gráfico seguinte. O fato de São Paulo concentrar a maior parcela do PIB nacional com certeza explica parcialmente a forte concentração bancária no Estado. Este argumento está de acordo com uma literatura de orientação keynesiana, que indica que em áreas de menor dinamismo econômico há maior preferência pela liquidez, dada a maior incerteza e os arranjos institucionais menos desenvolvidos. Por outro lado, os autores observam que essas áreas tendem a perder liquidez para as mais dinâmicas, seja por motivos reais (balança comercial), seja por financeiros (conta de capitais). Assim, as atividades bancárias (e financeiras, de modo geral) tenderão a concentrar-se nas localidades mais dinâmicas economicamente, porque os bancos, em áreas de pouco dinamismo, enfrentam dois problemas: a) perdem mais reservas para o público do que os localizados nas regiões mais prósperas, considerada a preferência pela liquidez nas menos dinâmicas; b) perdem reservas para as desenvolvidas.

\section{TABELA 5 - DISTRIBUIÇÃO REGIONAL DO PIB BRASILEIRO, EM \%}

\begin{tabular}{lccccccccccccc}
\hline & 1988 & 1989 & 1990 & 1991 & 1992 & 1993 & 1994 & 1995 & 1996 & 1997 & 1998 & 1999 & 2000 \\
\hline Estado SP & 38,14 & 37,77 & 37,02 & 35,25 & 35,49 & 34,88 & 34,15 & 35,47 & 34,93 & 35,47 & 35,46 & 34,94 & 33,67 \\
Estado RJ & 11,00 & 10,32 & 10,86 & 12,28 & 12,07 & 11,77 & 11,34 & 11,52 & 11,14 & 11,22 & 11,01 & 11,75 & 12,52 \\
Resto Reg. SE & 11,18 & 11,27 & 10,95 & 11,18 & 11,23 & 11,08 & 11,78 & 11,73 & 12,01 & 11,87 & 11,69 & 11,55 & 11,60 \\
Reg. Sul & 17,51 & 18,64 & 18,21 & 17,11 & 18,30 & 18,42 & 18,67 & 17,89 & 18,03 & 17,68 & 17,48 & 17,75 & 17,57 \\
Reg. NE & 12,83 & 12,30 & 12,86 & 13,37 & 12,92 & 12,82 & 12,87 & 12,78 & 13,17 & 13,09 & 13,05 & 13,11 & 13,09 \\
Reg. CO & 5,00 & 4,77 & 5,16 & 6,10 & 5,67 & 5,79 & 6,10 & 5,98 & 6,08 & 6,25 & 6,84 & 6,45 & 6,95 \\
Reg. Norte & 4,35 & 4,93 & 4,94 & 4,71 & 4,32 & 5,24 & 5,09 & 4,64 & 4,64 & 4,42 & 4,48 & 4,45 & 4,60 \\
\hline
\end{tabular}

Fonte: IBGE. Elaboração Própria.

No caso da RMSP, em razão do processo de "interiorização" da indústria, a concentração econômica não explica por si só a intensa concentração financeira. Como apon- 
tam Alexandre, Lima e Canuto (2005), a distribuição regional da atividade bancária não é proporcional à do PIB, o que indica que essa atividade não é mera sombra da econômica e que sofre a influência de determinantes locais específicas. Os autores sugerem que a maior concentração geográfica dessa atividade no Brasil explica-se, em boa parte, pela busca das instituições financeiras por ganhos de escala e de escopo. Como evidência, citam o estudo de Silva e Neto (2001), em que se constatam economias de escala no sistema bancário brasileiro após o Plano Real, independentemente do porte do banco.

Além disso, certamente os bancos e as demais instituições financeiras levam em consideração, em suas decisões locacionais, as externalidades favoráveis à atividade bancária. É a RMSP que concentra os serviços mais importantes e complexos e hospeda os principais fornecedores de serviços empresariais, os grandes escritórios de advocacia e de contabilidade, as empresas de auditoria e de informática, ou seja, há uma verdadeira rede de serviços e facilidades que possibilitam a atividade financeira. Além disso, a região apresenta externalidades, tais como capital humano altamente qualificado e infra-estrutura tecnológica para o funcionamento das operações financeiras. É muito provável que essas externalidades tenham desempenhado papel importante na decisão locacional da atividade bancária.

Foge ao propósito deste artigo analisar as origens da concentração das atividades financeiras na RMSP. ${ }^{1}$ Dessa perspectiva, basta ter claro que, nos últimos anos, principalmente após a estabilização monetária, intensificou-se o processo de concentração das atividades financeiras na RMSP. O que não é patente é se tal concentração significa um maior desenvolvimento financeiro da região em relação às concorrentes, $\mathrm{O}$ que, em parte, definiria o motivo das desigualdades de crescimento entre elas. $\mathrm{O}$ que se pretende elucidar no que segue é se, uma vez constatada tal concentração e a discrepância dela em relação à econômica na região, existe alguma relação de causalidade entre o desenvolvimento financeiro de São Paulo e seu crescimento econômico, ou se se trata apenas de uma ocorrência simultânea.

\section{ANÁLISE EMPÍRICA}

O estudo da relação entre o desenvolvimento financeiro e a atividade econômica locais, como ilustram vários dos trabalhos mencionados na seção 1 , tem sido tradicionalmente feito na literatura econômica por meio de testes de causalidade propostos por Granger. Desta forma, não fugindo à regra, optou-se por testar econometricamente

1 Como aponta Singer (1968), as raízes desse fenômeno podem estar ligadas à produção cafeeira paulista de meados do século XIX e a toda a rede de comércio e de serviços que ela impulsionou, de modo a criar um mercado consumidor cujo centro era a cidade de São Paulo. 
eventual precedência temporal, no sentido de Granger, entre variáveis financeiras e de crescimento econômico da RMSP.

\subsection{O Modelo}

Dada a escassez de variáveis disponíveis, optou-se por abordar a relação entre a atividade econômica e o crédito bancário na RMSP por meio da construção de um modelo de Vetores Auto-regressivos - VAR bivariado.

Em notação matricial um modelo VAR genérico assume a seguinte forma:

$$
X_{t}=\Pi_{1} X_{t-1}+\Pi_{2} X_{t-2}+\ldots+\Pi_{k} X_{t-k}+\varepsilon_{t}
$$

em que $X_{t}$ é um vetor $(N x I)$ de variáveis endógenas, $\varepsilon_{t} \sim(0, \Omega)$ é vetor de ruídos brancos, e $\Pi_{i}$ é uma matriz de coeficiente $(N x N)$.

Como no modelo a ser estimado são introduzidas algumas variáveis exógenas de controle, o modelo genérico acima sofre algumas alterações. As variáveis exógenas têm efeito contemporâneo sobre as variáveis endógenas, de modo que em notação matricial temos:

$$
X_{t}=\Pi_{1} X_{t-1}+\Pi_{2} X_{t-2}+\ldots+\Pi_{k} X_{t-k}+\Phi Z_{t}+\varepsilon_{t}
$$

cuja inovação está no vetor de variáveis exógenas, $Z_{t}$, e na matriz de coeficientes, $\Phi$.

No modelo a ser estimado a seguir, $X_{t}$ é um vetor $(2 \mathrm{xl})$ que comporta os indicadores financeiro e de atividade econômica e $Z_{t}$ representa as 3 variáveis de controle exógenas: desvio padrão mensal dos retornos diários do IBOVESPA, juros reais, e dummies de tempo.

\subsection{Apresentação dos Dados}

Como já se notou, encontrar uma medida representativa do desenvolvimento financeiro de cada região ou localidade não é trivial. Se, para a dimensão nacional, já é difícil existir consenso sobre as medidas mais representativas, na regional, pela escassez de dados, as limitações são ainda maiores. 
A solução encontrada foi usar, a exemplo da literatura de séries temporais que estuda os impactos do desenvolvimento financeiro, diferentes medidas de crédito como índices de desenvolvimento financeiro, a saber: crédito total, financiamentos, empréstimos e títulos descontados e desembolsos do BNDES. ${ }^{2}$

É interessante esclarecer quanto cada modalidade de crédito representa do total de cada área. No caso da RMSP, o estoque de financiamentos apresenta coeficiente médio, entre janeiro de 1995 e dezembro de 2003, de 19,2\%, enquanto o de empréstimos e títulos descontados é de 30,3\%. Como os desembolsos do BNDES estão medidos em fluxo, isto é, em novas concessões, não temos como avaliar qual a participação de seu estoque sobre o estoque de crédito total.

Com exceção dos desembolsos do BNDES, que constituem novas concessões, os dados sobre crédito municipal, disponíveis no Sistema de Informações do BACEN - SISBACEN -, apresentam algumas dificuldades para os nossos propósitos. Em primeiro lugar, os dados referem-se ao estoque total mensal do Sistema Financeiro Nacional, sem contabilizar o volume efetivo de novas concessões por mês. Em segundo lugar, não há distinção entre crédito livre e direcionado, somente informações sobre o agregado. Certamente, o ideal seria trabalhar com o crédito livre, que, de fato, reflete o comportamento dos intermediários financeiros locais.

Para se obter uma proxy do volume de novas concessões, optou-se por trabalhar com a diferença dos estoques das modalidades de crédito medidos em logaritmos. Este artifício nos dá uma medida do fluxo de novas concessões, que, por definição, é a variação dos estoques. Porém é preciso supor que as liquidações dos financiamentos e empréstimos sejam distribuídas de forma equilibrada ao longo do ano, senão um mês com número anormal de liquidações pode dar a errônea impressão de ter havido queda nas novas concessões, quando, na realidade, elas permaneceram estáveis ou até se elevaram.

No momento de escolher um indicador representante da atividade econômica da RMSP, levantaram-se diversas variáveis, como emprego, vendas do comércio, consumo de energia elétrica, entre outras. O emprego, ainda que representante essencial

2 Crédito Total: empréstimos e títulos descontados, financiamentos, financiamentos rurais de custeio, de investimento e de comercialização, financiamentos agroindustriais, financiamentos imobiliários, outros créditos (carteira de câmbio, créditos em liquidação etc.), menos provisão para operação de créditos. Financiamentos: a agentes financeiros, à exportação, em moedas estrangeiras, com interveniência, em atraso, e refinanciamento de operações de arrendamento e de operaçóes do Governo Federal, menos renda apropriada em financiamentos. Empréstimos e Títulos Descontados: adiantamento a depositantes, empréstimos, títulos descontados, renegociação especial para pessoas jurídicas, empréstimos e títulos descontados em atraso, menos renda apropriada em empréstimos e títulos descontados. Desembolsos do BNDES: Financiamento Para a Aquisição de Máquinas e Equipamentos - FINAME, BNDES automático, apoio à exportação; Financiamento a Empreendimentos - FINEM, financiamentos à marinha mercante e à construção naval, fundo social. 
do grau de aquecimento da economia e da qualidade do desenvolvimento econômico, não se mostrou sensível às diferentes modalidades de crédito e também parece não influir na dinâmica dessas variáveis, conforme testes preliminares. Por isso, desconsiderou-se o seu uso. Uma explicação possível para esse comportamento está no fato de o mercado de trabalho seguir, por natureza, o crescimento econômico e só reagir após a consolidação de um movimento de expansão ou de recessão. Uma vez descartado o uso do emprego, optou-se por utilizar o Indicador de Movimentação Econômica - IMEC - calculado pela FIPE, por ser um índice que engloba diferentes variáveis econômicas, inclusive as aventadas inicialmente.

A série histórica mensal desse indicador, formado pela média ponderada de variáveis dessazonalizadas relacionadas à movimentação de pessoas, além de ao consumo de combustíveis e energia elétrica e a indicadores do comércio, iniciou-se em janeiro de 1992. As variáveis se referem à Região Metropolitana de São Paulo ou à capital paulista. O setor informal também é captado pelo indicador, o que lhe confere maior abrangência na aferição da evolução do setor real da área. ${ }^{3}$

Na realidade, o IMEC não é indicador propriamente dito de atividade econômica, mas deve ser visto como uma proxy para a medição do nível dela. As variáveis que o compõem são endógenas e oscilam de acordo com as decisões de produção, de contratação de mão-de-obra, de investimento, de compra de insumos e de bens, de contratação de serviços etc. Contudo, além de monitorar a movimentação de mercadorias e de pessoas - certamente uma contrapartida das decisóes produtivas -, o IMEC também considera variáveis relacionadas a vendas do comércio e a consumo de energia, portanto mais próximas do conceito de atividade econômica. Os pesos das variáveis do índice são determinados pelo método dos Componentes Principais, que também garante a não incorporação de variáveis que apresentem elevado grau de correlação.

Com certeza, o crescimento econômico é causado por outras variáveis, além das creditícias, portanto utilizam-se variáveis de controle para reduzir possíveis problemas de omissão de variáveis. Empregam-se os juros reais, que contêm a expectativa dos agentes econômicos sobre a inflação futura, e o desvio padrão mensal dos retornos

3 O IMEC compõe-se das seguintes variáveis: pedágio comercial no sistema Anhangüera-Bandeirantes (Autoban) - dados diário; pedágio de passeio no sistema Anhangüera-Bandeirantes (Autoban) - dados diários; movimento de passageiros nos ônibus municipais (São Paulo Transportes) - dados diários; movimento de passageiros no metrô (Metrô) - dados diários; movimento de passageiros no Terminal Tietê (Socicam) - dados semanais; movimento de passageiros no Aeroporto de Congonhas (Infraero) - dados diários; consumo de gasolina no Estado de São Paulo (Petrobrás) - dados semanais; consumo de óleo diesel no Estado de São Paulo (Petrobrás) - dados semanais; consumo de energia elétrica na Grande São Paulo (EPTE) - dados diários; consultas ao Serviço de Proteção ao Crédito - SPC (Associação Comercial) - dados diários; consultas ao Telecheque (Associação Comercial) - dados diários. 
diários do IBOVESPA como controle para flutuações macroeconômicas, além das dummies de tempo, que captam impactos pontuais na economia. ${ }^{4}$

\subsection{Testes de Raiz Unitária}

Os testes de raiz unitária revelam que a variação dos estoques das modalidades de crédito e os desembolsos do BNDES são estacionários a 10\% de significância. Para o IMEC, não se rejeita a hipótese de raiz unitária a $10 \%$ de significância e, em conseqüência, para se evitar problemas de correlação espúria, o VAR estimado na próxima seção empregará o IMEC na primeira diferença.

TABELA 6 - TESTES DE RAIZ UNITÁRIA

\begin{tabular}{lcc}
\hline Variáveis (em log) & Teste ADF & Teste PP \\
\hline Indicadores de crédito & & \\
crédito & $-12.87^{* * *}$ & $-13.02^{* * *}$ \\
Empréstimos e títulos descontados & $-11.14^{* * *}$ & $-11.13^{\star * *}$ \\
Financiamentos & $-11.16^{* \star *}$ & $-11.17^{* * *}$ \\
Desembolsos BNDES & $-8.58^{* * *}$ & $-15.79^{\star * *}$ \\
Indicadores reais & & \\
IMEC & -1.697 & -1.7065 \\
\hline
\end{tabular}

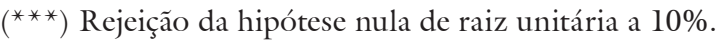

Obs. Com exceção do desembolsos do BNDES, os indicadores de crédito foram diferenciados.

\subsection{Testes de Causalidade de Granger}

Apresentam-se, agora, os resultados dos testes de causalidade na RMSP, referentes à estimativa do modelo VAR bivariado.

A Tabela 7 apresenta os resultados do teste de causalidade utilizando a variação do estoque de crédito total emitido na RMSP. O modelo com 3 defasagens, o melhor segundo o critério AIC, aponta a existência de bicausalidade entre o crédito e a variação do IMEC a $10 \%$ de significância. A $5 \%$ de significância, há indícios de causalidade da variável financeira apenas para a real. Mesmo que se acrescente uma defasagem ao modelo, o crédito continua a ser um indicador antecedente do IMEC, a 10\% de significância, o que não ocorre no sentido inverso.

4 A conveniência do IBOVESPA também deriva de sua característica de indicador do desenvolvimento financeiro do País. Além disso, fornece um número de observações superior ao que seria fornecido, por exemplo, pelo PIB. Para se medirem os juros reais, desconta-se do CDI acumulado de cada mês a inflação mensal, calculada pelo IGP-DI. 


\section{TABELA 7 - CRÉDITO X IMEC}

\begin{tabular}{lccc|ccc}
\hline & \multicolumn{3}{c|}{ H0: Crédito NGC IMEC } & \multicolumn{3}{c}{ H0: IMEC ÑGC crédito } \\
\hline Lags & 3 & 4 & 5 & 3 & 4 & 5 \\
P-valor & 0,037 & 0,065 & 0,148 & 0,079 & 0,117 & 0,209 \\
\hline Autocorrelação & 0,257 & 0,198 & 0,298 & 0,257 & 0,198 & 0,298 \\
AlC & $-7,63$ & $-7,57$ & $-7,39$ & $-7,63$ & $-7,57$ & $-7,39$ \\
\hline
\end{tabular}

A análise da relação entre a variação do estoque de financiamentos e o IMEC (Tabela 8) aponta a existência de bicausalidade. Os resultados são contundentes neste sentido: em todos os modelos, a hipótese de não-causalidade de Granger, tanto dos financiamentos em direção ao IMEC quanto na inversa, foi rejeitada a 5\% de significância.

TABELA 8 - FINANCIAMENTOS X IMEC

\begin{tabular}{lccc|ccc}
\hline & \multicolumn{3}{c|}{ H0: Financiamentos ÑGC IMEC } & \multicolumn{3}{c}{ H0: IMEC ÑGC financiamentos } \\
\hline Lags & 3 & 4 & 6 & 3 & 4 & 6 \\
P-valor & $\mathbf{0 , 0 1 7}$ & $\mathbf{0 , 0 0 5}$ & $\mathbf{0 , 0 1}$ & $\mathbf{0 , 0 1 4}$ & $\mathbf{0 , 0 0 8}$ & $\mathbf{0 , 0 4 1}$ \\
\hline Autocorrelação & 0,128 & 0,407 & 0,217 & 0,128 & 0,407 & 0,217 \\
AlC & $-9,149$ & $-9,272$ & $-9,111$ & $-9,149$ & $-9,272$ & $-9,111$ \\
\hline
\end{tabular}

A série de dados de empréstimos e títulos descontados apresenta uma quebra estrutural, provocada pela eclosão da Crise Asiática em outubro de 1997. Desta forma, optou-se por estimar o modelo utilizando a amostra inteira e as duas subamostras resultantes dessa quebra estrutural. Os testes para a primeira subamostra (de janeiro/92 a outubro/97) indicam, contundentemente, uma relação de precedência temporal de mão dupla entre os empréstimos e títulos descontados e o IMEC. A relação de bicausalidade verifica-se em praticamente todos os modelos avaliados, porém este resultado não se mantém quando utilizadas a segunda subamostra (de janeiro/98 a dezembro/03) e a amostra inteira. Em ambos os casos, as hipóteses de não-causalidade não podem ser rejeitadas.

Chama a atenção a diferença de comportamento da causalidade entre os dois subperíodos. Uma explicação plausível para isso é de que o segundo subperíodo foi marcado por uma série de choques macroeconômicos que gerou grande incerteza quanto ao comportamento futuro da economia e certamente afetou a disponibilidade de concessão de empréstimos e títulos descontados. É imprescindível ressaltar a maxidesvalorização de janeiro de 1999, a crise energética em meados de 2001 e a mudança de governo em 2003. Além disso, o período iniciou-se logo após a Crise Asiática. 
TABELA 9 - EMPRÉSTIMOS E TIT. DESC. X IMEC (JAN./92 - OUT./97)

\begin{tabular}{lccc|ccc}
\hline & \multicolumn{3}{c|}{ H0: Empréstimos ÑGC IMEC } & \multicolumn{3}{c}{ H0: IMEC ÑGC empréstimos } \\
\hline Lags & 2 & 4 & 6 & 2 & 4 & 6 \\
P-valor & $\mathbf{0 , 0 0 0}$ & $\mathbf{0 , 0 0 0}$ & $\mathbf{0 , 0 0 0}$ & $\mathbf{0 , 0 6 1}$ & $\mathbf{0 , 0 9 8}$ & 0,357 \\
\hline Autocorrelação & 0,143 & 0,15 & 0,119 & 0,143 & 0,15 & 0,119 \\
AlC & $-10,629$ & $-10,272$ & $-9,824$ & $-10,629$ & $-10,272$ & $-9,824$ \\
\hline
\end{tabular}

TABELA 10 - EMPRÉSTIMOS E TIT. DESC. X IMEC (JAN./98 - DEZ./03)

\begin{tabular}{lccc|ccc}
\hline & \multicolumn{3}{c|}{ H0: Empréstimos ÑGC IMEC } & \multicolumn{3}{c}{ H0: IMEC ÑGC empréstimos } \\
\hline Lags & 1 & 4 & 6 & 1 & 4 & 6 \\
P-valor & 0,474 & 0,970 & 0,998 & 0,962 & 0,612 & 0,864 \\
\hline Autocorrelação & 0,202 & 0,294 & 0,313 & 0,202 & 0,294 & 0,313 \\
AlC & $-9,261$ & $-8,857$ & $-8,576$ & $-9,261$ & $-8,857$ & $-8,576$ \\
\hline
\end{tabular}

TABELA 11 - EMPRÉSTIMOS E TIT. DESC. X IMEC (JAN./92 - DEZ./03)

\begin{tabular}{lccc|ccc}
\hline & \multicolumn{3}{c|}{ H0: Empréstimos ÑGC IMEC } & \multicolumn{3}{c}{ H0: IMEC ÑGC empréstimos } \\
\hline Lags & 3 & 4 & 6 & 3 & 4 & 6 \\
P-valor & 0,614 & 0,681 & 0,785 & 0,512 & 0,71 & 0,795 \\
\hline Autocorrelação & 0,357 & 0,638 & 0,481 & 0,357 & 0,638 & 0,481 \\
AlC & $-9,612$ & $-9,52$ & $-9,364$ & $-9,612$ & $-9,52$ & $-9,364$ \\
\hline
\end{tabular}

Segundo a Tabela 12, os empréstimos do BNDES não sofrem qualquer influência da atividade econômica da RMSP e também parecem não acrescentar informação relevante para a previsão dela ao longo do período amostral. Este resultado não é surpreendente, visto que os desembolsos destinados à cidade de São Paulo não são muito significativos em volume, em razão da grande participação do setor de serviços na região, além de os dados se referirem apenas à cidade, e não à RMSP.

TABELA 12 - BNDES X IMEC

\begin{tabular}{lccc|ccc}
\hline & \multicolumn{3}{c|}{ H0: BNDES ÑGC IMEC } & \multicolumn{3}{c}{ H0: IMEC ÑGC BNDES } \\
\hline Lags & 3 & 4 & 6 & 3 & 4 & 6 \\
P-valor & 0,679 & 0,670 & 0,850 & 0,143788 & 0,211 & 0,402 \\
\hline Autocorrelação & 0,956 & 0,171 & 0,215 & 0,956 & 0,171 & 0,215 \\
AlC & $-3,371$ & $-3,357$ & $-3,113$ & $-3,371$ & $-3,357$ & $-3,113$ \\
\hline
\end{tabular}


Os resultados desta seção revelam comportamento diferente da relação entre as modalidades de crédito financiamentos e empréstimos e títulos descontados e a atividade econômica da RMSP, medida pelo IMEC. Enquanto os financiamentos apresentam relação bicausal com o IMEC, o mesmo não ocorre com os empréstimos e títulos descontados que, nas estimativas para a amostra toda e para o segundo período, não exibem relação causal direta ou reversa com o IMEC, mas para o período de janeiro de 1992 a setembro de 1997 apresentam relação bicausal.

Uma explicação possível para essa discrepância está na natureza das atividades que cada modalidade de crédito tende a custear. Os financiamentos empregam recursos nas operações com fins específicos, como parques industriais, máquinas e equipamentos, bens de consumo durável etc., isto é, a finalidade do empréstimo é anunciada quando do fechamento do contrato. Assim, a instituição emissora do financiamento parece ter melhores condições de avaliar o risco de inadimplência da operação, ou ainda pode usar o próprio objeto do financiamento como colateral. Por outro lado, os empréstimos são operações realizadas sem destinação específica ou vínculo com a comprovação da aplicação dos recursos. Por isso, do ponto de vista das instituições financeiras, a concessão de financiamentos pode vir a oferecer menor risco do que a de empréstimos e títulos descontados.

Num período cheio de incertezas, como foi aquele entre a Crise Asiática e o final de 2003, é natural que as instituições financeiras tenham preferido as concessões de financiamentos em prejuízo das operações de empréstimos e títulos descontados ou passassem a cobrar taxas de empréstimos mais altas para cobrir a percepção de maior risco. Talvez isto explique a diferença de resultados obtidos nos modelos com empréstimos e títulos descontados, estimados nas duas subamostras.

Esse padrão de causalidade verificado na RMSP vai ao encontro das conclusões de Vasconcelos et alii (2003). Assumindo-se que a relação crédito bancário/PIB é pequena no Brasil, os autores consideram baixa a elasticidade do crédito em relação ao PIB e indicativa de que o crédito ofertado pelos bancos, em vez de ser um elemento impulsionador do crescimento econômico, reflete uma posição passiva e conservadora do sistema bancário brasileiro. $\mathrm{O}$ fato de apenas os financiamentos terem mostrado alguma precedência temporal sobre o crescimento econômico da RMSP reforça essa visão, porque, em comparação com os empréstimos e títulos descontados, possuem componente maior de recursos direcionados. A visão de Singer (1968), de que o crédito não comanda o desenvolvimento econômico, mas segue-o e intensifica-o, parece válida para o período analisado.

Por fim, importa salientar que, no caso da RMSP, mesmo que os recursos representados pelas diferentes variáveis de crédito se destinem a outros locais, seja do interior 
de São Paulo ou de outros Estados, essas atividades demandam uma série de serviços só encontrados na metrópole, o que desencadeia efeito multiplicador sobre a economia da região. Nesse contexto, a constatação da bicausalidade para a RMSP estaria muito mais associada ao perfil fornecedor de serviços à produção que a região tem do que à qualidade das variáveis de crédito propriamente dita. Com efeito, os dados da PAEP demonstram claramente a forte presença do setor de serviços nesse espaço e, como alega Tinoco (2001), o funcionamento dos serviços à produção é marcado pela interação ou pela complementaridade.

\section{CONSIDERAÇÕES FINAIS}

Existem fortes evidências de que a macrorregião do Estado e da RMSP consolidouse nos anos 1990 como o principal centro financeiro nacional, em prejuízo, principalmente, da praça financeira da cidade do Rio de Janeiro, que lhe cedeu espaço gradualmente. A capital paulista, em particular, passou a sediar os principais bancos nacionais e internacionais ativos no País, além de monopolizar a execução das operações financeiras mais sofisticadas, quer pelas bolsas de valores com sede na capital, quer pelas diferentes instituiçôes financeiras.

Seguindo a literatura especializada no estudo empírico da direção de causalidade entre desenvolvimento financeiro e crescimento econômico, avaliou-se, por meio do teste de Granger, a direção causal entre variáveis reais e de crédito na RMSP. Os resultados revelam que a relação entre o desenvolvimento financeiro e a atividade econômica é de bicausalidade ou retroalimentação.

No caso da RMSP, sua natureza de centro comercial e, principalmente, ofertante de serviços à produção, como constatada por Tinoco (2001), parece influir na relação entre a atividade econômica local e as modalidades de crédito. A causalidade partindo do crédito para o crescimento econômico estaria mais associada à quantidade de serviços desencadeados pela concessão do crédito na região do que propriamente à qualidade deste, seja no quesito volume, spread ou prazo. Como grande centro de negócios do País, a RMSP concentra não apenas os serviços financeiros, mas atrai também as empresas prestadoras de serviços empresariais e seus profissionais mais especializados. Mesmo que o destino do recurso financeiro emprestado seja aplicado em outra região, a RMSP se beneficia indiretamente pela demanda de serviços que esta aplicação irá desencadear. 


\section{REFEREANCIAS BIBLIOGRÁFICAS}

Alexandre, M.; Biderman, C.; Lima, G. T. Distribuição regional do crédito bancário e convergência no crescimento estadual brasileiro. Anais do XXXII Encontro Nacional de Economia, João Pessoa: ANPEC, dez. 2004.

Alexandre, M.; Lima, G. T.; Canuto, O. Distribuição espacial da atividade bancária no Brasil: dimensões e indicadores. Revista Nova Economia, Belo Horizonte, v. 15, n. 1, p. 11-33, jan.-abr. 2005.

Azzoni, C. R. Induistria e reversão da polarização no Brasil. IPE/USP, 1986. (Mimeografado).

Castro, C. B. Moeda e espaço: os casos das áreas metropolitanas de São Paulo, Rio de Janeiro, Belo Horizonte, Curitiba, Salvador e suas áreas de polarização. 2002. Dissertação (Mestrado), CEDEPLAR, UFMG. Belo Horizonte.

Chick, V.; Dow, S. C. A post-keynesian perspective on the relation between banking and regional development. In: Arestis, P. (ed.), Post-keynesian monetary econom$i c s$ : new approaches to financial modelling. Aldershot: Edward Elgar, 1988, p. 219-250.

Diniz, C. C. Desenvolvimento poligonal no Brasil: nem desconcentração nem contínua polarização. Revista Nova Economia, Belo Horizonte, v. 3, n. 1, p. 3564, 1993.

Dow, S. C. European monetary integration and the distribution of credit availability. In: Corbridge, Stuart; Thrift, Nigel; Martin, Ron (eds.), Money, power and space. Oxford: Blackwell, 1994, p. 149-164.

Guiso, L.; Sapienza, P.; Zingales, L. Does local financial development matter? CEPR Discussion Papers 3307, 2002.

Granger, C. W. J. Investigating causal relations by econometric models and crossspectral methods. Econometrica, 37, p. 424-438, 1969.

Hirschman, A. O. The strategy of economic development. New Haven: Yale University, 1958.

Jayaratne, J.; Strahan, P. E. The finance-growth nexus: evidence form bank branch deregulation. Quarterly Journal of Economics, 111, p. 639-70, ago. 1996.

Kaldor, N. The case for regional policies. Scottish Journal of Political Economy, v. 17, n. 3, p. 337-348, 1970.

Levine, R. Financial development and economic growth: views and agenda. Journal of Economic Literature, XXXV, p. 688-726, 1997.

Lima, G. T. Evolução recente da regulação bancária no Brasil. In: Sobreira, R. (org.), Regulação financeira e supervisão bancária. São Paulo: Editora Atlas, 2005.

Marques Jr., T. E.; Porto Jr., S. Desenvolvimento financeiro e crescimento econômico no Brasil - Uma avaliação econométrica. PPGE-UFRGS, 2003. (Mimeografado). 
Martin, R.; Minns, R. Undermining the financial basis of regions: the spatial structure and implications of the UK pension funds system. Regional Studies, 29, p. 125-44, 1995.

Matos, O. C. de. Desenvolvimento do sistema financeiro e crescimento econômico no Brasil: evidências de causalidade. Brasília, Trabalhos para Discussão do Bacen, 49. Set/2002.

Mishkin, F. S. Financial consolidation: dangers and opportunities. NBER Working Paper, n. 6655, 1998.

Myrdal, G. Economic theory and under-developed regions. London: Gerald Duckworth, 1957.

Pacheco, C. A. A questão regional brasileira pós 1980: desconcentração econômica e fragmentação da economia nacional. 1996. Tese (Doutorado), UNICAMP, Campinas.

Perroux, F. A economia do século XX. Lisboa: Herder, 1967.

Sicsú, J.; Crocco, M. Em busca de uma teoria da localização das agências bancárias: algumas evidências do caso brasileiro. Economia, v. 4, n. 1, jan./jun. 2003.

Silva, T. L.; Neto, P. M. J. Economia de escala nos bancos brasileiros após o Plano Real. Texto para Discussão 227. Fortaleza: CAEN-UFC, julho de 2001.

Singer, P. Desenvolvimento econômico e evolução urbana. São Paulo: Editora Nacional, 1968.

Sobrinho, N. F. S. Uma avaliação do canal de crédito no Brasil. 2002. Dissertação (Mestrado), FEA-IPE/USP, São Paulo.

Tinoco, A. C. Competitividade, inovação e localização: repensando o conceito de centralidade da região metropolitana de São Paulo. 2001. Dissertação (Mestrado), CEDEPLAR-UFMG, Belo Horizonte.

Townroe, P. M.; Keen, D. Polarization reversal in the state of São Paulo. Regional Studies, v. 18, n. 1, 1984.

Vasconcelos, M. et alii. O todo e as partes: uma análise da desigualdade de crédito entre os estados brasileiros e os determinantes do crédito bancário com a aplicação de dados em painel. Anais do XXXI Encontro Nacional de Economia, ANPEC, 2003.

Zimmerman, G. C. Implementing the single banking market in Europe. Federal Reserve Bank of San Francisco Economic Review, p. 35-51, 1995. 